\title{
Calculation of water environmental capacity of Puzhehei Lake
}

\author{
SUN Lei ${ }^{1}$, MA Wei ${ }^{1}$, BAN Jing-ya ${ }^{1}$, QI De-xuan ${ }^{1}$ \\ ${ }^{1}$ China Institute of Water Resources and Hydropower Research, Institute of water ecological environment, Beijing, China
}

\begin{abstract}
The calculation of water environmental capacity of Puzhehei lake is of great significance for preventing water pollution and protecting water ecological environment of Puzhehei Lake Basin. Based on the lack of hydrological and water quality data in Puzhehei Lake Basin, a large number of basic data were collected through pollution source investigation and water quality monitoring. On this basis, a twodimensional hydrodynamic water quality model of Puzhehei lake was established by using Mike21 model to simulate the migration and diffusion of pollutants into the lake. The current situation of pollution load in Puzhehei lake was analyzed, and the characteristics of water flow, hydrodynamic force and the migration and diffusion law of pollutants in Puzhehei Lake were analyzed. The results show that: (1) the annual loads of COD, TN, TP and $\mathrm{NH}_{3}-\mathrm{N}$ in puzhehai Lake in 2018 are 4090.0t, 401.3t, 34.4t and 122.6t; (2)Puzhehei lake is mainly non-point source pollution, and the difference of water environmental capacity between non rainy season and rainy season is very significant.
\end{abstract}

\section{Introduction}

In recent years, lakes are playing a more and more important role in the planning of urban tourism construction. The lake not only has tourism value, such as promoting the development of local and surrounding businesses and increasing residents' income, but also has ecological value such as improving the local ecological environment, regulating flood and storing water ${ }^{[1]}$.

Water environmental capacity refers to the maximum carrying amount of a certain pollutant that can be contained in the water area in unit time under a given water area and designed hydrological conditions to meet the water environmental quality standards. At present, the calculation methods of water environmental capacity in China mainly include formula method, probability dilution model method and model trial and error method. Zheng Yao et al. established EFDC model and used linear programming method to calculate the water environmental capacity of Chongqing reservoir area. $\mathrm{Hu}$ Bingqing et al. improved the probabilistic dilution model and improved its operability. Wu Hui et al. used onedimensional water quality model to calculate the water environmental capacity of river basin, and put forward ecological management countermeasures. At downstream switch-off black lake water storage, water level rise slow speed, less water self-purification ability and water environmental capacity is reduced, and as the black's popularity to rise, more and more tourists into the lake pollution load increase gradually, thus easy to cause in local area of the lake district blooms and the eutrophication environmental problems to be solved. Given the application of numerical simulation methods in lakes, the application of numerous maturation is currently in China, and there is less research on the black lake in the country. Therefore, in order to clearly understand the water quality and nanoid capacity of the generals, this study is based on Mike21 model, constructing The hydrodynamic and water quality model of the black lake, the simulated pollutant time and space change process, calculating the water environment capacity of the general black lake, providing theoretical basis for the auction of water ecological restoration in the generals ${ }^{[2]}$.

\section{Materials and Methods}

\subsection{0verview of the study area}

Puzhehei Lake is located in the north of Qiubei County, $11 \mathrm{~km}$ from Qiubei County and $114 \mathrm{~km}$ from Wenshan Prefecture. It is located between $104^{\circ} 03$ ' $22^{\prime \prime} \sim 104^{\circ} 09^{\prime}$ 07" east longitude and $24^{\circ} 09$ '56 " 24이' $58^{\circ}$ " north latitude. Puzhehei Lake is a part of the Xijiang River system in the Pearl River Basin. It flows from the outlet into Qingshui River and then into Nanpan River and finally into the Pearl River. Puzhehei Lake is located in the Puzhehei Lake Basin, which is famous for the idyllic scenery of karst landscape. Puzhehei Lake Group is composed of more than 80 karst lakes distributed in Puzhehei Basin ${ }^{[3]}$. It is a natural shallow water lake in karst area, with a length of about $20 \mathrm{~km}$ and a surface area of about $13 \mathrm{~km}^{2}$.Among them, Puzhehei Lake, Luoshuidong Lake and Xianrendong Lake are connected in a zonal distribution. The average width of the lake is $250 \mathrm{~m}$, the average depth is $3-8 \mathrm{~m}$, and the deepest is $30 \mathrm{~m}$. 


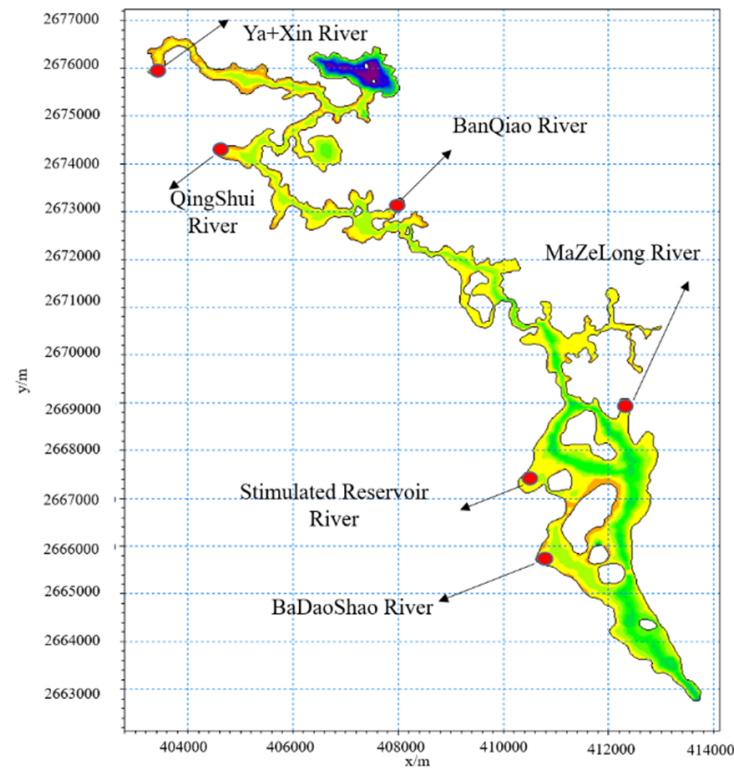

Fig. 1 Schematic diagram of hydrographic net of Puzhehei Lake Basin

\subsection{Model construction}

\subsubsection{Boundary conditions}

Mike's boundary conditions include three parts: lakeshore boundary, lake entry boundary, and lake exit boundary. The lakeshore boundary adopts the condition of no slip of the water flow, and the velocity of the water flow along the shore is zero. The boundary of lake entry generally consists of hydrodynamic boundary and water quality boundary. (1) Hydrodynamic boundary: according to the water and land boundary conditions of river course, six water boundary conditions are set according to the river entering the lake: $\mathrm{Ya}+$ xinhe, banqiao river, hongqi reservoir (with the pendulum longhu/qingshui river), ma river, river reservoir to increase production and eight whistle river tributaries, the prediction basin or measured data as inlet boundary conditions of model calculation, from January 2018 to 12 month lake river flow boundary as shown in figure, according to the survey of the load into the lake. Due to the large pollutant emission of Puzhehei $\mathrm{B} \& \mathrm{~B}$, it is generalized as a point source with an average flow of $0.005 \mathrm{~m}^{3} / \mathrm{s}$. (2) Water quality boundary. According to the survey results of pollutants entering the lake in each river unit entering the lake in 2018, it is assumed that the point source emissions are basically stable in the year, and the non-point source emissions fluctuate with the influence of monthly rainfall in the year. In addition, considering the high concentration load of initial rainwater, the annual distribution of the load entering the lake in 2018 is conducted. The water quality boundary conditions of each river in Puzhehei Lake were obtained by modifying the water quality concentration process based on the estimated flow process and the annual load distribution results with the limited measured water quality data. According to the average value of monitoring data, the initial control concentration of water quality in the lake area is determined. The results show that COD is
$20 \mathrm{mg} / 1, \mathrm{TN}$ is $0.5 \mathrm{mg} / 1$, TP is $0.028 \mathrm{mg} / 1$ and $\mathrm{NH}_{3}-\mathrm{N}$ is $0.42 \mathrm{mg} / \mathrm{l}$. In order to eliminate the influence of unreasonable water level boundary setting on the actual discharge process of Puzhehei Lake, there is basically no routine monitoring for the discharge volume and water level of Puzhehei Lake ${ }^{[4]}$.

\subsubsection{Key parameter selection}

(1)Dry-wet boundary: the default parameters in MIKE21 model were adopted in this study, namely, dry water depth $\mathrm{h}_{\text {dry }}=0.005 \mathrm{~m}$, submerged water depth $\mathrm{h}_{\text {flood }}=0.05 \mathrm{~m}$, and wet water depth $h_{w e t}=0.1 \mathrm{~m}$. That is, when the water depth in the calculation area is less than $0.005 \mathrm{~m}$, the calculation area is "dry" and does not participate in the calculation. When the water depth is greater than $0.1 \mathrm{~m}$, the water area is considered as "wet" and should be included in the calculation.

(2)Diffuse coefficient and degradation coefficient: Under the action of topography and perennial dominant wind field, the average velocity of Puzhehei Lake is about $1-1.6 \mathrm{~cm} / \mathrm{s}$, which is less than the river entering the lake, so the diffusion coefficient $\mathrm{D}$ is chosen as $1 \mathrm{~m}^{2} / \mathrm{s}$.

According to the measured water quality data of Puzhehei Lake in 2018 and the investigation of lake loading, the concentration of pollutants entering the lake was calculated, and the degradation coefficients of various water quality factors were determined. Finally, the degradation coefficients of COD, TN,TP and $\mathrm{NH}_{3}-\mathrm{N}$ in Puzhehei Lake were $\mathrm{K}_{\mathrm{COD}}=0.05 \mathrm{~d}^{-1} 、 \mathrm{~K}_{\mathrm{TN}}=0.025 \mathrm{~d}^{-1}$ 、 $\mathrm{K}_{\mathrm{TP}}=0.009 \mathrm{~d}^{-1}$ and $\mathrm{K}_{\mathrm{NH} 3-\mathrm{N}}=0.025 \mathrm{~d}^{-1}$, respectively.

\subsection{Model validation}

\subsubsection{Verification of hydrodynamic models}

Since there is basically no routine monitoring of the lake outlet level of Puzhehei Lake, the simulated average lake outlet water level of April and August 2018 at the outlet of Puzhehei Lake is $1445.23 \mathrm{~m}$ and $1444.86 \mathrm{~m}$ respectively, which is basically consistent with the measured water level value of $1445.31 \mathrm{~m}$ and $1444.80 \mathrm{~m}$. That is, through analysis, the hydrodynamic model can be used for the hydrodynamic characteristics of Puzhehei Lake. The specific fitting situation is shown in the fig.2.

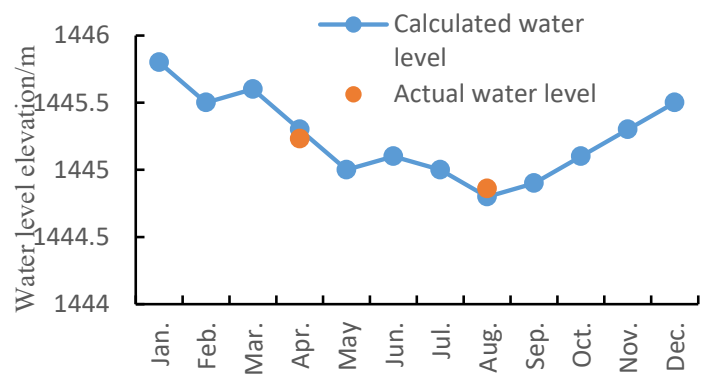

Fig. 2 Verification diagram of point water level of Puzhehei Lake outlet in 2018 


\subsubsection{Verification of water quality model}

Water quality model verification uses the monitoring data for the measured point of the Sino-Sangfang and Qingshui River into the lake in the black and cultural resection of the Water River in the Water River in 2018. Fig.3 show the results of the calculated value and the measured point $\mathrm{COD}$ and $\mathrm{TN}$ concentration of the desperate measurement point $\mathrm{COD}$ and $\mathrm{TN}$ concentration in the hunter, and the results of the measured value, which is $27.58 \%, 18.20 \%$, respectively, by $27.58 \%, 18.20 \%$, respectively, by comparison results. It is less than $30 \%$, which proves that the parameter ratio is relatively reliable, and basically reflects the process of water quality changes in the black lake in the black lake, which can be used for the calculation of the actual water environmental capacity of the designer black lake.
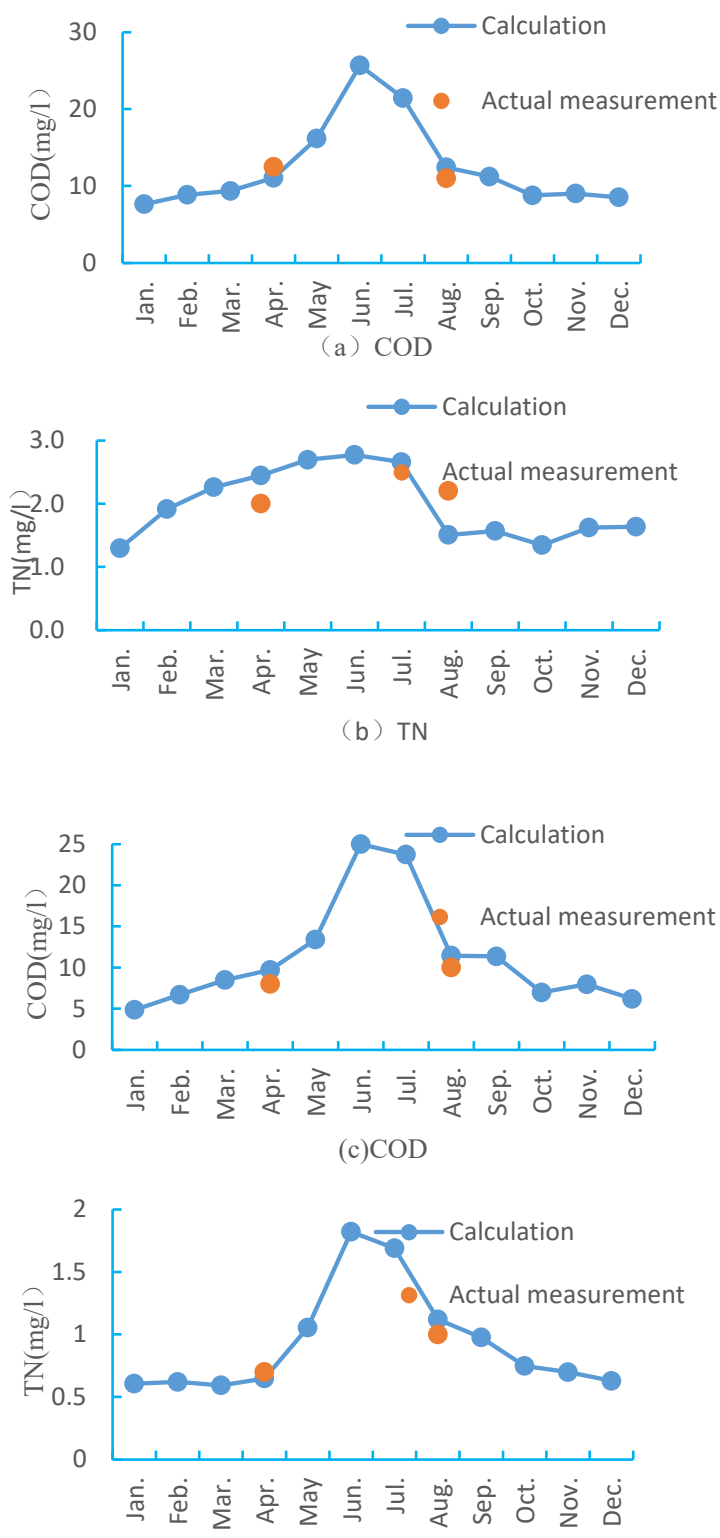

(d)TN

Fig. 3 Water quality verification map of Puzhehei Lake in 2018

\section{Result and Discussion}

\subsection{Analysis of model results}

The simulation results show that the water velocity in the lake area is obviously affected by topography, dominant wind field and the inflow of large tributaries. During the dry season from January to April, the inflow of the lake area is small and the water level is high, which makes the flow velocity of the lake area slow, with an average flow velocity of $1 \sim 1.6 \mathrm{~cm} / \mathrm{s}$. In the wet season from July to September, the inflow of the lake is large and it rains more in summer, so the overall flow velocity of the lake is large, with an average flow velocity of $3-4 \mathrm{~cm} / \mathrm{s}$. Weeks at the same time by the lake terrain conditions, earth's rotation, the bathymetry, dominated the lake wind field and such comprehensive effect, sink lake on circulation, at black lower east side structure is dominated by small and medium-sized counterclockwise circulation form, at the downstream of the black west mainly counterclockwise circulation structure and so on, and change as the change of the lakes wind field.

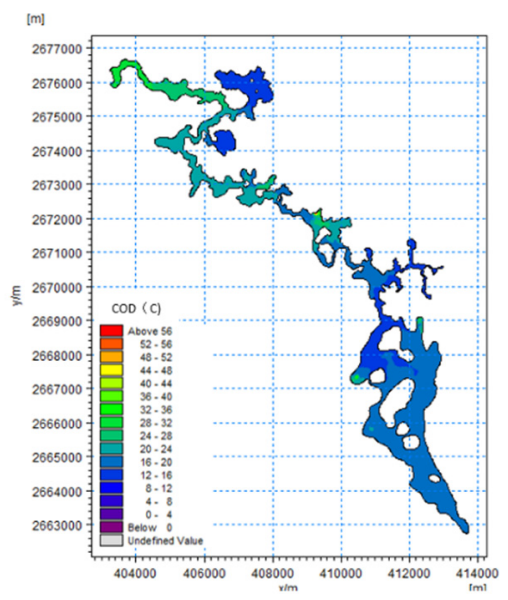

(a) $\mathrm{COD}$

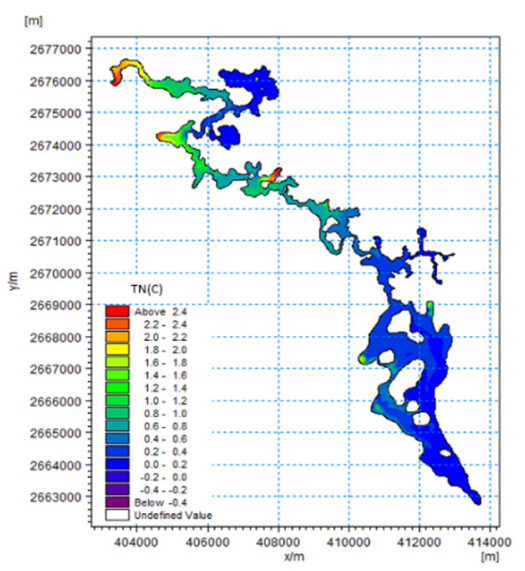

(b) $\mathrm{TN}$

Fig. 4 Spatial distribution of pollutants in Puzhehei Lake in 2018

According to the simulation of pollutant concentration field, as shown in Fig.4, the length and area of the pollution zone from the entrance of Ya+Xinhe River to the 
middle reaches of Puzhehei are gradually longer and larger than those of the lower reaches. As can be seen from the figure, the concentrations of COD and TN in the upper and middle reaches of Puzhehei Lake all exceed the limit, the concentrations of local TP in the middle reaches exceed the limit, and the overall water quality in the lower reaches is relatively good. According to the spatial distribution characteristics of water quality in the lake area, the water quality in the lower reaches of Puzhehei Lake is gradually improving from south to north due to the comprehensive influence of the heavy pollution of the Changshuang Reservoir River and Ya+Xin River and the hydrodynamic conditions in the lake area. However, the water quality in the middle reaches of Puzhehei Lake is poor due to the influence of tourism and catering industry.

\subsection{Water environmental capacity calculation}

\subsubsection{Calculation conditions}

Point sources in Puzhehei Basin are mainly from urban sewage, with a small annual variation and stable discharge. Only point sources from Puzhehei Bed and Stays directly discharge into the lake, while other point sources enter the lake through the river course. Due to the obvious difference between the non-point source and the point source, the non-point source can only be generated when there is continuous rainfall and runoff is formed, and the runoff load pollution caused by early rainfall is more serious. Therefore, two groups of calculation schemes were set up in this study. (1) the water environmental capacity of Puzhehei Lake during the dry season was calculated under the hydrological boundary conditions of the average inflow flow process of the driest month (April) and the average water level $(1445.5 \mathrm{~m})$ under the condition of the typical hydrological year $2018(\mathrm{P}=90 \%)$ calculated by the hydrological department by reduction. (2) The average monthly inflow and average monthly water level in 2018 were used as the hydrological boundary conditions to calculate the dynamic water environmental capacity of Puzhehei Lake.

\subsection{Calculation results and analysis}

With the above calculation conditions as the boundary, the trial-and-error method was adopted to continuously change the pollutant concentration of the main tributaries according to the flow and location factors of each tributary, until the concentration of the control section (or water quality monitoring station) reached the upper limit of the water quality control target of the lake. At this time, the product of pollutant concentration, discharge and corresponding time of each branch into the lake is the allowable pollutant discharge volume of Puzhehei Lake in this period of time of this branch. Through calculation, the allowable sewage discharge (water environmental capacity) of COD, TN, TP and $\mathrm{NH}_{3}-\mathrm{N}$ in Puzhehei Lake were obtained. The detailed calculation results are shown in Tab.1 and Tab.2.
Tab. 1 Calculation results of water environmental capacity of Puzhehei Lake and each lake entry unit in dry season

(unit: t/a)

\begin{tabular}{|c|c|c|c|c|}
\hline \multirow{2}{*}{ Unit } & \multicolumn{4}{|c|}{ Water environmental capacity in dry season } \\
\cline { 2 - 5 } & COD & $\mathbf{T N}$ & $\mathbf{T P}$ & $\mathbf{N H}_{3}-\mathbf{N}$ \\
\hline ZCSK & 47.9 & 2.3 & 0.5 & 2.3 \\
\hline BQ & 7.3 & 2.2 & 0.1 & 0.8 \\
\hline BDS & 167.8 & 7.9 & 1.3 & 5.3 \\
\hline Y+X & 68.1 & 3.4 & 0.6 & 3.4 \\
\hline MZL & 289.5 & 14.5 & 1.3 & 8.0 \\
\hline QS & 50.5 & 1.8 & 0.1 & 1.5 \\
\hline ZCSK & 309.4 & 18.6 & 3.1 & 10.3 \\
\hline Summary & $\mathbf{9 4 0 . 4}$ & $\mathbf{5 0 . 6}$ & $\mathbf{6 . 9}$ & $\mathbf{3 1 . 6}$ \\
\hline
\end{tabular}

Tab. 2 Calculation results of dynamic water environmental capacity of Puzhehei Lake and each lake entry unit

\begin{tabular}{|c|c|c|c|c|}
\hline \multirow{2}{*}{ Unit } & \multicolumn{3}{|c}{ Dynamic water environmental capacity } \\
\cline { 2 - 5 } & COD & TN & TP & NH3-N $_{3}$ \\
\hline ZCSK & 190.0 & 9.5 & 1.8 & 9.5 \\
\hline BQ & 7.3 & 2.2 & 0.1 & 0.8 \\
\hline BDS & 703.0 & 35.1 & 6.6 & 26.4 \\
\hline Y+X & 282.3 & 15.1 & 2.8 & 15.1 \\
\hline MZL & 1297.7 & 64.9 & 6.5 & 40.6 \\
\hline QS & 179.3 & 9.6 & 0.4 & 7.2 \\
\hline ZCSK & 1222.2 & 65.2 & 12.2 & 40.7 \\
\hline Summary & $\mathbf{3 8 8 1 . 7}$ & $\mathbf{2 0 6 . 6}$ & $\mathbf{3 0 . 3}$ & $\mathbf{1 4 0 . 2}$ \\
\hline
\end{tabular}

It can be seen from Tab.1and2 that the average monthly discharge water environmental capacity of COD, $\mathrm{TN}, \mathrm{TP}$ and $\mathrm{NH}_{3}-\mathrm{N}$ of Puzhehei Lake is $3881.7 \mathrm{t} / \mathrm{a}$, 206.6t/a, 30.3t/a and 140.2t/a, respectively. $(\mathrm{P}=90 \%)$ in the driest month (April), COD, TN, TP, NH3-N are 940.4t/a, 50.6t/a, 6.9t/a, 31.6t/a, respectively. The dynamic water environmental capacity of Puzhehei Lake accounted for $24.2 \%, 24.5 \%, 22.8 \%$ and $22.5 \%$ of the corresponding pollutants, respectively. In addition, in this study, the water environmental capacity calculated by the average discharge of the driest month $(\mathrm{P}=90 \%)$ was taken as the total point source discharge control quantity of Puzhehei Basin, and the water environmental capacity calculated by the average discharge of the driest month $(\mathrm{P}=90 \%)$ minus the water environmental capacity calculated by the average discharge of the driest month $(\mathrm{P}=90 \%)$ was taken as the total point source control quota. In other words, the discharge of Puzhehei Lake non-point source into the lake is $2941.3 \mathrm{t} / \mathrm{a}, 156.0 \mathrm{t} / \mathrm{a}, 23.4 \mathrm{t} / \mathrm{a}$ and $108.6 \mathrm{t} / \mathrm{a}$, respectively.

\section{Conclusion}

(1) In order to study the water environmental capacity of Puzhehei lake, Mike21 model and trial and error method were used in this study to understand the impact of point source and non-point source pollution in Puzhehei basin. Therefore, two sets of schemes are set up to calculate the average discharge water environment capacity (COD 940.4t/a 、TN 50.6t/a、TP 6.9t/a and NH3-N 31.6t/a) and 
the average discharge water environment capacity in the driest month $(\mathrm{P}=90 \%)$, The results show that $(\mathrm{P}=90 \%)$ the average discharge water environmental capacity of the driest month only accounts for about $20 \%$ of the monthly average discharge water environmental capacity, which indicates that the Puzhehei lake is mainly non-point source pollution, and the difference of water environmental capacity between non rainy season and rainy season is very significant.

(2) Through the total amount control analysis of the water environment capacity in the dry season and the dynamic water environment capacity, it is concluded that the dynamic water environment capacity can better represent the actual water environment capacity of Puzhehei Lake than the water environment capacity in the dry season.

\section{References:}

1. Zhao Xianghua, Wang Zhiyun. Restoration and Management Countermeasures of Puzhehei lakeside zone [J]. Yunnan Environmental Science, 2005 (S1): $82-85$.

2. Wang Yan, Liu yungen, Liang Qibin, Hou Lei. Change of area of Puzhehei Lake in dry season from 1977 to 2014 [J]. Wetland science, 2016,14 (04): 471476.

3. Wen Guojing, Liu yungen, Wang Yan, Hou Lei, Wang Yanxia, Guo Yujing. Spatiotemporal evolution of landscape pattern and ecological risk in Puzhehei Lake Basin [J]. Journal of Zhejiang agriculture and Forestry University, 2017,34 (06): 1095-1103.

4. Yu Xin, Zhou Yanwen, min Xinghua. Study on combined mathematical model of water environment and pollutant reduction in Shijiu Lake Basin [J]. Hydropower energy science, 2021,39 (02): 31-34. 